\title{
How ICT can contribute to realize a sustainable society in the future: a CGE approach
}

\author{
Xiaoxi Zhang $^{1}$ (D) Machiko Shinozuka ${ }^{1} \cdot$ Yuriko Tanaka $^{2} \cdot$ Yuko Kanamori $^{3}$. \\ Toshihiko Masui ${ }^{3}$
}

Received: 1 November 2020 / Accepted: 19 July 2021 / Published online: 5 August 2021

(c) The Author(s) 2021

\begin{abstract}
Many information and communications technology (ICT) services have become commonplace worldwide and are certain to continue to spread faster than before, particularly along with the commercialization of $5 \mathrm{G}$ and movement restrictions in response to the COVID19 Pandemic. Although there is a concern that ICT equipment usage may increase power consumption and emit greenhouse gas (GHG) emissions, ICT has also been contributing to reducing GHG emissions through improved productivity and reduced mobility. This research targeted the main ICT services used in Japan and adopted a dynamic national computable general equilibrium model to quantitatively analyze future impacts on economic growth and GHG emission reduction until 2030 by using these ICTs, while considering both the increase in power consumption of ICT itself and the reduction in environmental load in other sectors. The results showed that the spread of ICT services, especially some artificial intelligence-based services, can improve productivity in most sectors through labor-saving and contribute to improving overall gross domestic product (GDP). Additionally, increased efficiency of logistics and manufacturing can greatly reduce the input of oil and coal products and so greatly contribute to GHG emission reduction. In 2030, compared with the baseline scenario in which all technology levels are fixed at current levels, at least $1 \%$ additional GDP growth and $4 \%$ GHG emission reduction can be expected by the targeted introduction of ICT in the ICT accelerated scenario in which the technology level of ICT accelerates. This also means ICT can potentially decouple the economy from the environment.
\end{abstract}

Keywords ICT · Environmental impacts · GHG emissions · GDP · Scenarios · CGE model $\cdot$ Digital technologies

Xiaoxi Zhang

xiaoxi.zhang.bc@hco.ntt.co.jp

1 Space Environment and Energy Laboratories, NTT, 3-9-11, Midori-Cho, Musashino-Shi, Tokyo 180-8585, Japan

2 NTT Advanced Technology Corporation, 3-9-11, Midori-Cho, Musashino-Shi, Tokyo 180-8585, Japan

3 National Institute for Environmental Studies (NIES), 16-2, Onogawa, Tsukuba, Ibaraki 305-8506, Japan 


\section{Background and research issues}

Over the last two decades, great progress has been made in information and communications technology (ICT). Industrial ICT and daily online ICT services have become commonplace worldwide. ICT, as an industry, has already and will continue to have a major impact on economic and societal activities, such as GDP growth, employment, productivity, and quality of life (Palvia, 2017). ICT is also greatly contributing to improvements in productivity across industry (Oulton, 2002).

ICT has not only contributed to economic growth and convenience of life but also reduced environmental impacts. ICT can be used to make our patterns of production and consumption more sustainable (Hilty and Aebischer, 2014). For example, ICT enables more of us to work from home, thus reducing travel-related GHG emissions. Many sharing services reduce raw material use. ICT improves production efficiency and reduces the input of intermediate raw materials. The Global e-Sustainability Initiative estimated that ICT could generate over US $\$ 11$ trillion in economic benefits per year by 2030 ; at the same time, ICT use could also enable the world to cut its global emissions by $12,000 \mathrm{Mt}-\mathrm{CO} 2 \mathrm{eq}$ across 8 fields including smart buildings, smart mobility, etc. (GeSI, 2015). These can be considered as positive effects of ICT use on the environment. Therefore, ICT could also be considered as a GHG emission reduction measure to tackle the global issue of this century, climate change (IPCC, 2014).

However, technological developments such as AI, IoT, 4G, and future commercialization of $5 \mathrm{G}$ have brought about a large increase in communication traffic data. The reasons for this increase include a higher numbers of Internet users, more devices and connections, faster broadband speeds, and increased video viewing (Barnett, 2018). Increases in energy consumption and GHG emissions attributed to the ICT sector, which have a negative effect on the environment, are becoming an increasing concern. The International Telecommunication Union Telecommunication Standardization Sector (ITU-T) reported the baseline GHG emissions of global ICT sector development in 2030 will be 1.3 times that in 2015, without considering developments in the power sector (L.1470, 2020). Another study also estimated that in the worst-case scenario, the global electricity usage of ICT could contribute up to $23 \%$ of global GHG emissions by 2030 (Anders, 2015).

Economic recovery and GHG reduction are both important, especially in the post-pandemic era. The question for us is while ICT boosts economic growth, whether or not the positive effects of ICT's increasing permeation into various sectors of the economy will outweigh negative effects associated with increased power consumption. In other words, can we use ICT sustainably to decouple economic growth and its environmental impacts?

To answer the above question, it is very important to grasp the overall future environmental and economic impacts of ICT use including positive and negative effects. Methods have been proposed to assess the positive and/or negative effects of ICT use (GeSI, 2015; Pohl, 2019; Moyer, 2012; L.1410, 2014; L.1451, 2019; Erdmann, 2010; Bastida, 2019; Nagao, 2017). Taking a bottom-up approach for individual ICT services, Recommendation L.1410 published by ITU-T proposed a method for the environmental lifecycle assessment (LCA) of ICT goods, networks, and services (L.1410, 2014). The method can well understand $\mathrm{CO}_{2}$ emissions from each life stage of ICT use. However, it is more suitable for specifically analyzing individual ICT, since it requires many detailed micro-level data, and it has difficulty grasping the whole effects at a country level or for future forecasts. Researchers at Accenture used a more macro-method based on 12 ICT use cases (such as "E-health") (Bieser, 2018). They estimated the level of ICT adoption and the impacts on 
GHG emission of ICT adoption in each use case and compared them with the baseline. Furthermore, there are effects of ICT use that are more complex, such as rebound effects and spillover effects across industries (Lorenz, 2014). Rebound effects negatively affect the intended positive effects (Bomhof, 2009). Several studies have mentioned that $\mathrm{CO}_{2}$ emission reduction may rebound depending on the types of individual ICT (Gossart, 2015; James, 2019; Galvin, 2015; Takahashi, 2004). However, the above methods have difficulty covering all these impacts completely, especially when considering the future impact. To grasp the overall impacts at a macro-level, including the complex effects, computable general equilibrium (CGE) analysis as a top-down approach is more suitable than the above bottom-up approach. It can help us grasp the economic and industrial structural changes caused by the technologies spreading not only at present but also in the future and understand the impacts on not only the economy but also the environment. CGE analysis is usually used for analyzing the effects of general economic policies and various energy and climate policies. For example, several studies have analyzed GHG emission reduction effects and economic effects of environmental measures, such as introducing carbon taxes and expanding use of renewable energy and cleaner technologies (Chunark, 2017; Boonpanya, 2021; Matsumoto, 2011; Oshiro, 2017). However, few studies have analyzed the environmental effects of ICT usage from this approach, due to the complexity of expressing and assessing the effects of ICT introduction in the CGE model and the large amount of actual effect data required. Our previous study combined a bottom-up approach (mainly based on the LCA method) and a top-down approach (CGE analysis method) (Zhang, 2020). In the previous study, the direct effects of introducing ICT services are investigated and estimated mainly on the basis of the LCA approach and are expressed in the CGE model. The authors developed a dynamic CGE model to forecast the future macroeconomic and environmental impacts until 2030 by using some of the main ICT services in Japan. However, it focused mainly on the positive effects caused by ICT usage but hardly considered the increases in Internet traffic and changes in energy consumption caused by using ICT equipment, which is also a big concern for the future as mentioned above.

The purpose of this research is to quantitatively analyze future overall impacts of ICT usage in Japan on the economy and environment, considering both positive and negative effects on the environment, respectively. This will allow us to clarify whether economic growth from ICT can be decoupled from its and environment impacts. This will enable ICT to be used more sustainably and help to design policies that encourage environmentally advantageous utilization of ICT, while inhibiting uses that increase the speed of GHG emissions and resource consumption.

\section{Estimation method}

\subsection{Basic structure of the CGE model}

The model used in this research is based on the dynamic national CGE model for Japan, Asia-Pacific Integrated Model/Computable General Equilibrium (AIM/CGE [Japan]) (Masui, 2003). Its advantage is that it can treat different technologies including ICTs, so the model can analyze the impacts on economic and environment aspects by introducing these technologies. The CGE model in this research is calibrated with the 2005 Input-Output (IO) Tables in Japan (MIC, 2009). It has 49 sectors and 43 commodities, and electricity production is disaggregated into 10 sectors by power generation technologies as shown in 
"Appendix 1.1". Figure 1 shows the basic structure of the CGE model. The model contains four blocks: production sector, final consumption sector, market, and overseas sector.

\subsubsection{Production sector and final consumption sector}

The production sector uses production factors (e.g., capital and labor) and intermediate inputs (e.g., energy and raw materials) to produce products and supply them to the market. The production sector conducts production activities to maximize their profits subject to the availability of their production technologies. The final consumption sector holds the production factors, provides them to the production sector, and receives income as pay. Utility is calculated from the final consumption using the Cobb-Douglas function, and the purchased amount of consumption is determined to maximize the utility, subject to the constraints of budgets and commodity prices. Appendix 1.1 details the structure for production activities and final consumption.

\subsubsection{Market equilibrium condition for the CGE model}

Under the economic balance, a price mechanism determines levels of activity in each sector and prices for all goods, services, and production factors. That means that if demand exceeds supply, then prices will rise. Conversely, if demand is less than supply, prices will fall. The model's equations also include a set of constraints that have to be satisfied by the system as a whole. The key equations used in the model are listed in Appendix 1.1 and can be referred to (Masui, 2003).

\subsubsection{Overseas sector}

The production is distributed for export and domestic use. Here, a constant elasticity of transformation (CET) function with constant deformation elasticity is assumed. The

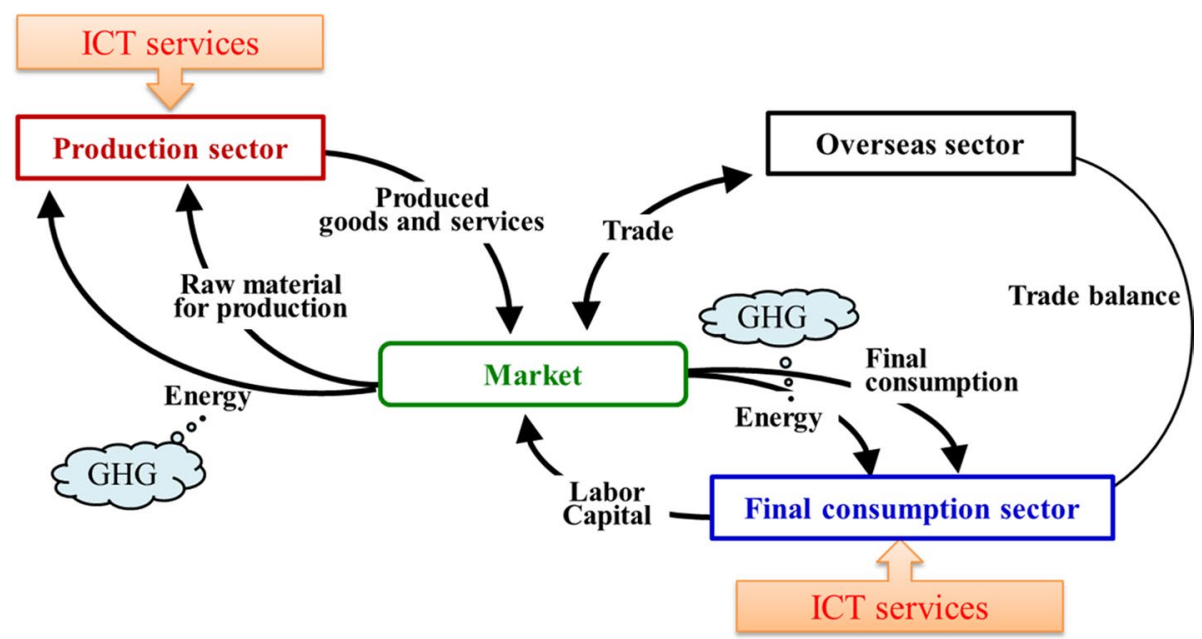

Fig. 1 Structure of CGE model 
domestic markets are integrated with domestic goods and imported goods by the constant elasticity of substitution (CES) function.

\subsubsection{Environment loads treated in the model}

The main environmental load treated in the model is GHG emissions. GHG emissions from each sector in the model in the base year are reconstructed on the basis of GHG emission data estimated by the Greenhouse Gas Inventory Office of Japan (GIO, 2019) and are adjusted to reproduce Japan's total GHG emissions. The emissions from energy sources are calculated in accordance with the amount of energy consumed in each sector, and other emissions are calculated in proportion to the amount of activities in each sector. Furthermore, in addition to GHG emissions, this research also briefly analyzes the impacts on raw material consumption, including resource use.

\subsection{Introduction of ICTs}

When production sectors and the final consumption sector introduce ICTs, demand from these sectors for ICT services will increase, which will bring about positive effects. For example, ICT usage is expected to increase production efficiency in the production sector and consumption efficiency in the final consumption sector, which means the intermediate inputs required per unit of production will be reduced. Production automation will save more labor. Using supply and demand matching technologies will reduce loss and waste and so reduce production. In this research, the authors investigated a large amount of statistical data and related reports (e.g., MICa, 2019; NEDO, 2016) and estimated these kinds of direct effects on production and consumption activities caused by introducing ICTs and expressed the direct effects by changing the IO coefficients in corresponding sectors in the CGE model. Due to these changes, the related market will be temporarily out of equilibrium. The CGE model can calculate to balance the supply and demand in each market on the basis of a price mechanism for each good and production factor.

\subsection{Dynamic progress}

For dynamic progress, as mentioned in the previous section, the model parameters are calibrated to replicate the IO Tables in the base year, 2005 (MIC, 2009). Figure 2 shows the process of capital accumulation and productions in our dynamic CGE model. Equilibrium calculation starts from 2005. Productions in sector $\mathrm{j}$ are used for intermediate demand, final demand, investment, and additional investment for introducing ICTs. The investment can be used as new capital for not only the existing technology and ICT in sector $\mathrm{j}$ but also other sectors $\mathrm{j}$ ' in the following year, 2006. To maximize profit in the equilibrium calculation, the model endogenously decides the allocation of the new capital. However, in this model, once the new capital is introduced into one sector, it cannot be moved. Existing capital stock in sector $\mathrm{j}$ will be used for the same sector in the following year taking depreciation into account. Then, capital stock in 2006 is determined by existing capital stock in the previous year (2005), depreciation rate, and investment from 2005. Depending on the technology levels of existing capital stock and new capital investment, the model calculates efficiency levels in each sector in 2006, such as energy efficiency. Moreover, the equilibrium solution in 2006 will be calculated on the basis of the prepared efficiency levels. The model will calculate the equilibrium solution year by year. 


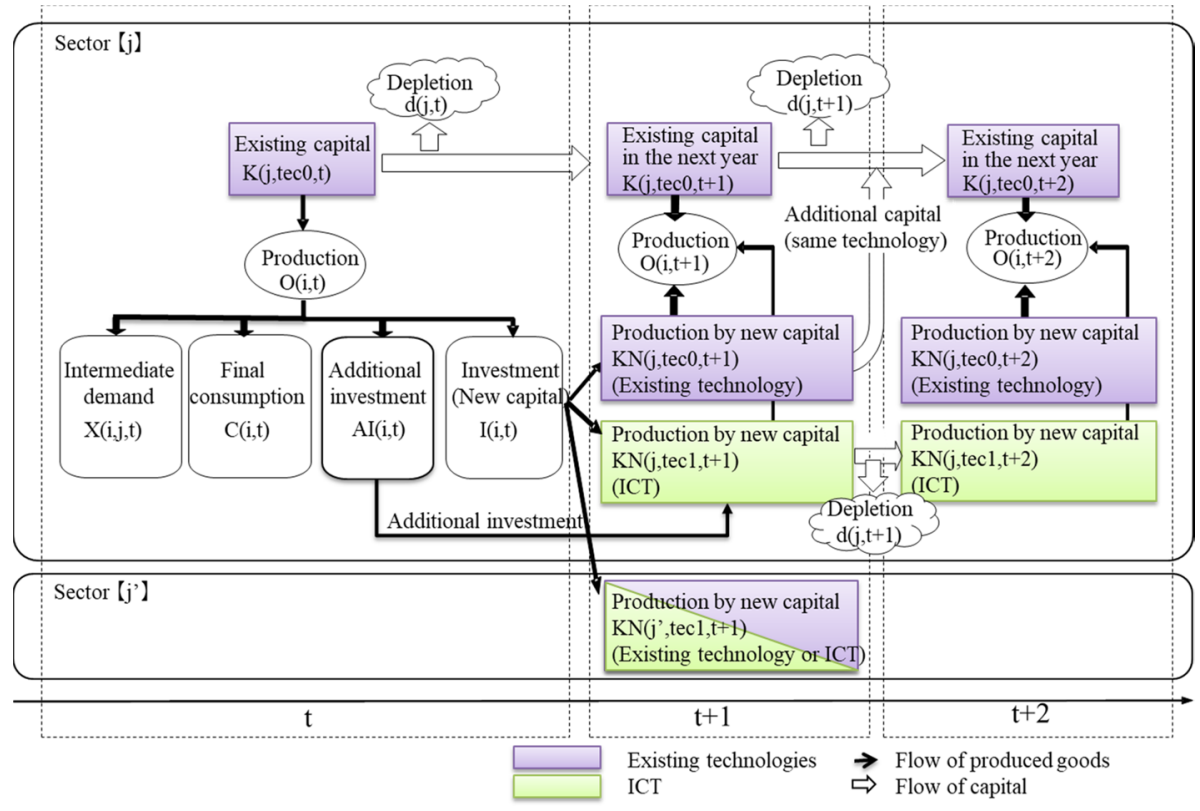

Fig. 2 Process of capital accumulation in the dynamic CGE model

In this model, the ICT services will be introduced by allocating the new capital for ICT services. That is to say, the retrofitting of ICT services to existing capital is not assumed in this model. New capital is provided to ICT services year by year, and expansion in the share of new capital provided to ICT services expresses the spread of ICT services. The amount of ICT introduced determines the additional investment for ICT endogenously in the model.

\subsection{Input data and future baseline scenario}

The CGE model calibrated the necessary parameters using the IO Table in Japan in 2005 (MIC, 2009). For a future scenario from 2016 to 2030, Table 1 shows basic preconditions,

Table 1 Preconditions in future baseline scenario

\begin{tabular}{lllll}
\hline & & 2005 year & 2015 year & 2030 year (estimation) \\
\hline Population & & 127.8 million & 126.6 million & 116.6 million \\
Households & & 49.0 million & 53.4 million & 54.7 million \\
GDP growth rate & & $1.2 \% /$ year & $0.9 \% /$ year & $1.7 \% /$ year \\
Power supply configuration & Renewable & $8 \%$ & $13 \%$ & $22 \sim 24 \%$ \\
& Nuclear & $31 \%$ & $1 \%$ & $20 \sim 22 \%$ \\
& LNG & $23 \%$ & $41 \%$ & $27 \%$ \\
& Coal & $27 \%$ & $35 \%$ & $26 \%$ \\
& Oil & $11 \%$ & $10 \%$ & $3 \%$ \\
\hline
\end{tabular}


such as population changes, expected gross domestic product (GDP) growth rate, and change in power supply configuration, which are set on the basis of Japan Intended Nationally Determined Contributions (MOFA, 2015).

\section{Target ICT services and future ICT scenarios}

\subsection{Target ICT services}

The paper targeted 36 kinds of ICT services used in six industry categories: finance, public services, manufacturing, distribution and services, medical and agriculture, and infrastructure. All 36 kinds of ICT services are divided into two groups. Group 1 includes ICT services that are already common, such as teleworking and online shopping. These ICT services are already maturing and have relatively high utilization rates according to statistical data in Japan (MICa, 2019). Group 2 contains relatively new ICT services, such as AI and IoT. Even though these ICT services have not spread as widely as the first group of ICT services in Japan, they have already started to be used in some industries, like manufacturing and distribution and services, and are expected to greatly reduce GHG emissions in the near future. Table 2 lists ICT services of Groups 1 and 2. The shaded cells represent the ICT services in Group 2, and the others represent the ICT services in Group 1.

\subsection{Direct effects expected by ICT introduction}

Direct effects caused by ICT introduction (such as reduction of movement and materials and optimization of intermediate distribution and retail sales) are set the same as those in a previous study (Zhang, 2020) and are also listed in Table 2. For Group 1, since the services are already in common use, many data can be collected from official statistics (e.g., MICa, 2019), and direct effects are mostly estimated on the basis of these statistical data. For Group 2, direct effects expected by using these ICTs are surveyed by forecast reports for future ICT and some use cases that have already been introduced in manufacturing factories and banking (Nikkei BP, 2016; NEDO, 2016). The values of the direct effects are estimated by the total amount of the evaluated activity and the amount reduced by ICT use and will be fed back to the intermediate input coefficient of the CGE model.

\subsection{Future ICT scenario}

To evaluate the impacts by using ICT, there are two main scenarios: baseline and ICT accelerated. Table 2 lists their details. For both scenarios, input data between 2005 and 2015 are set the same and are based on statistical data. To clarify the effectiveness of the ICT services independently, in the baseline scenario, energy efficiency for all technologies from 2016 to 2030 is assumed to be fixed at the level in 2015. In the ICT accelerated scenario, changes in ICT utilization rates and direct effects are set until 2030. Regarding the utilization rates, for Group 1, most data have been collected from related latest statistical data from 2008 to 2018 (e.g., MICa, 2019). The past data on utilization rates were fitted with the most fitted function and extrapolated until 2030. It can be seen that the utilization rates are quite different even in the same group. Less than half of the ICTs have utilization rates higher than 50. Therefore, the utilization rates of ICT technology can be believed to still have a lot of room for improvement and can be reasonably predicted to continue to 


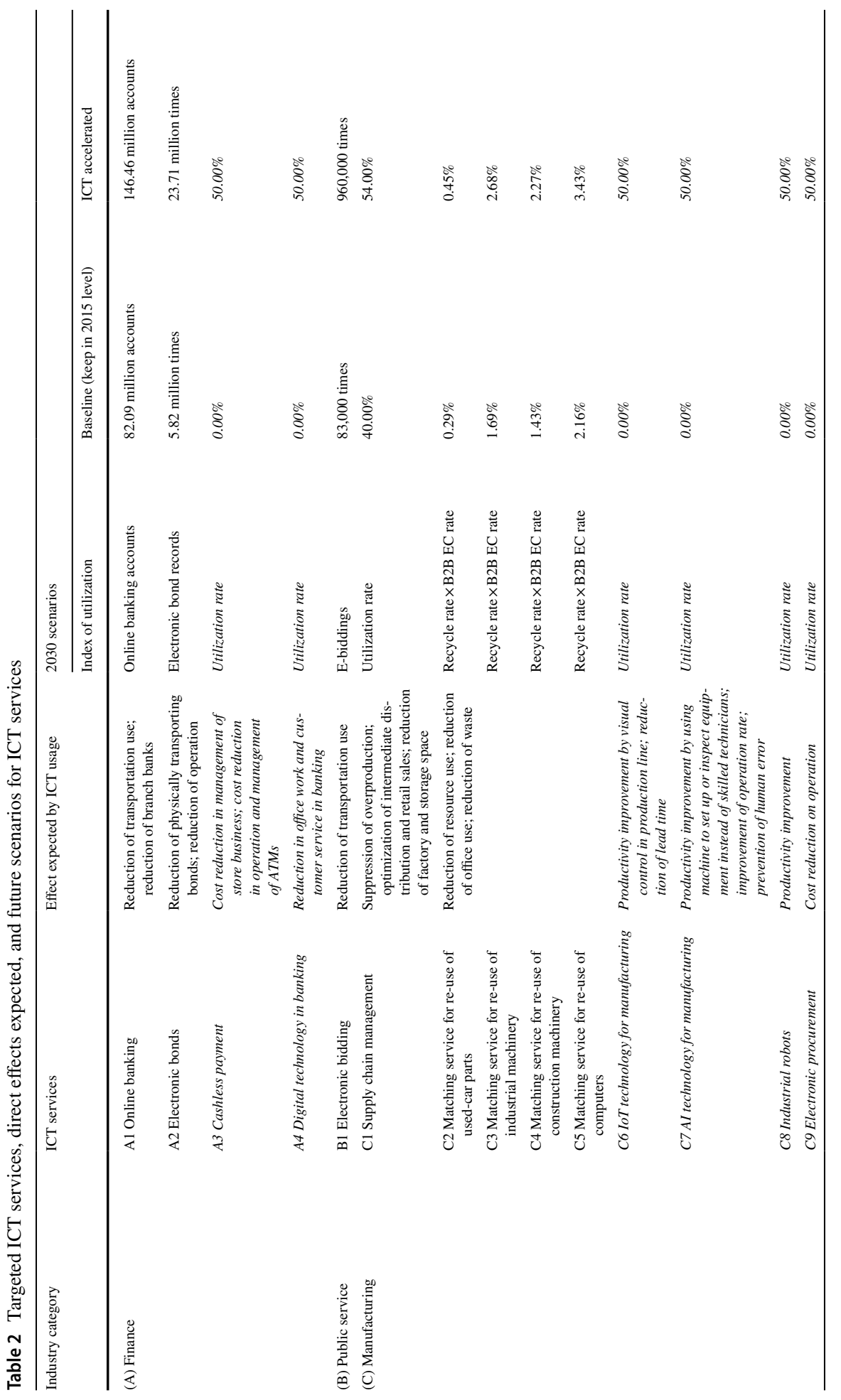




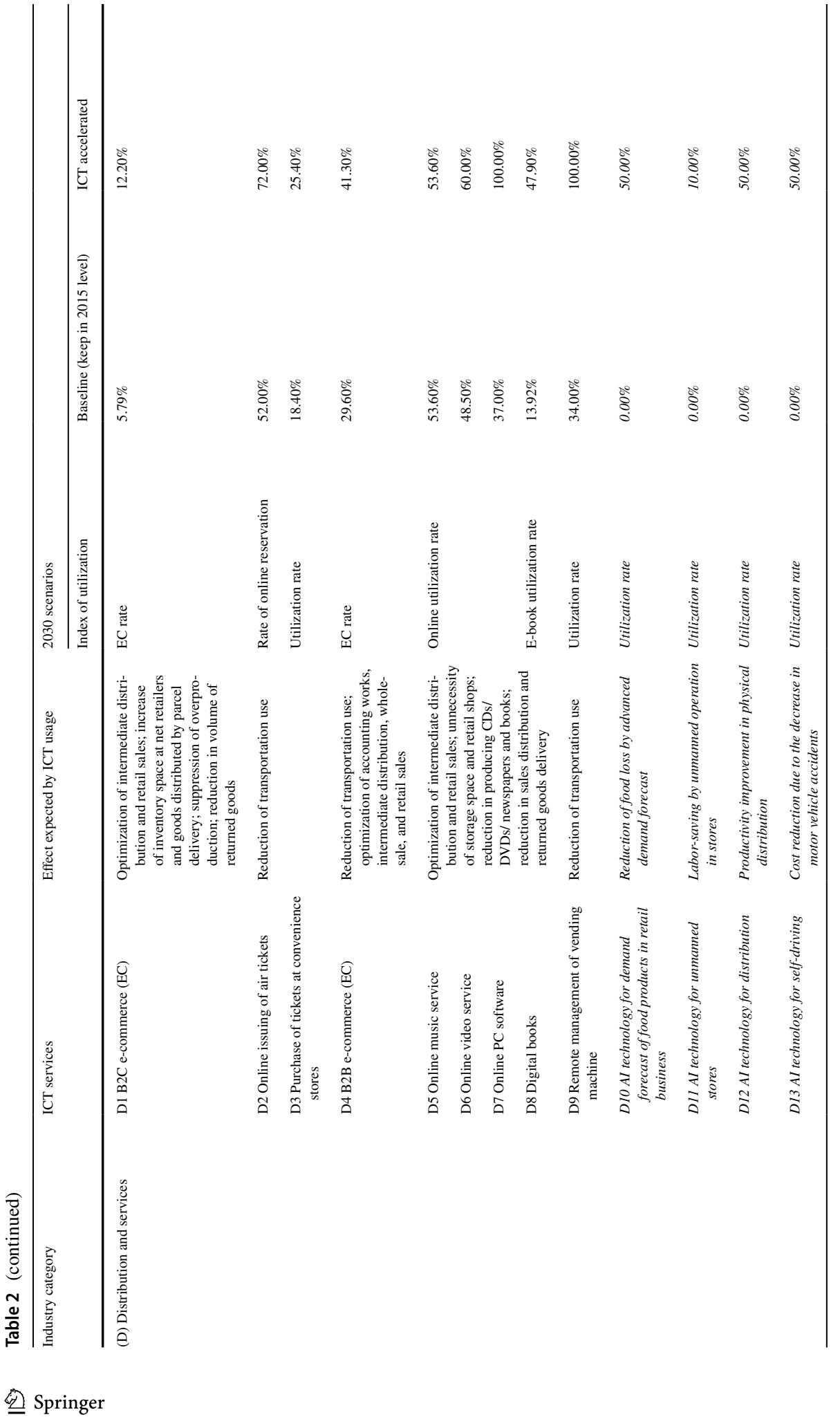




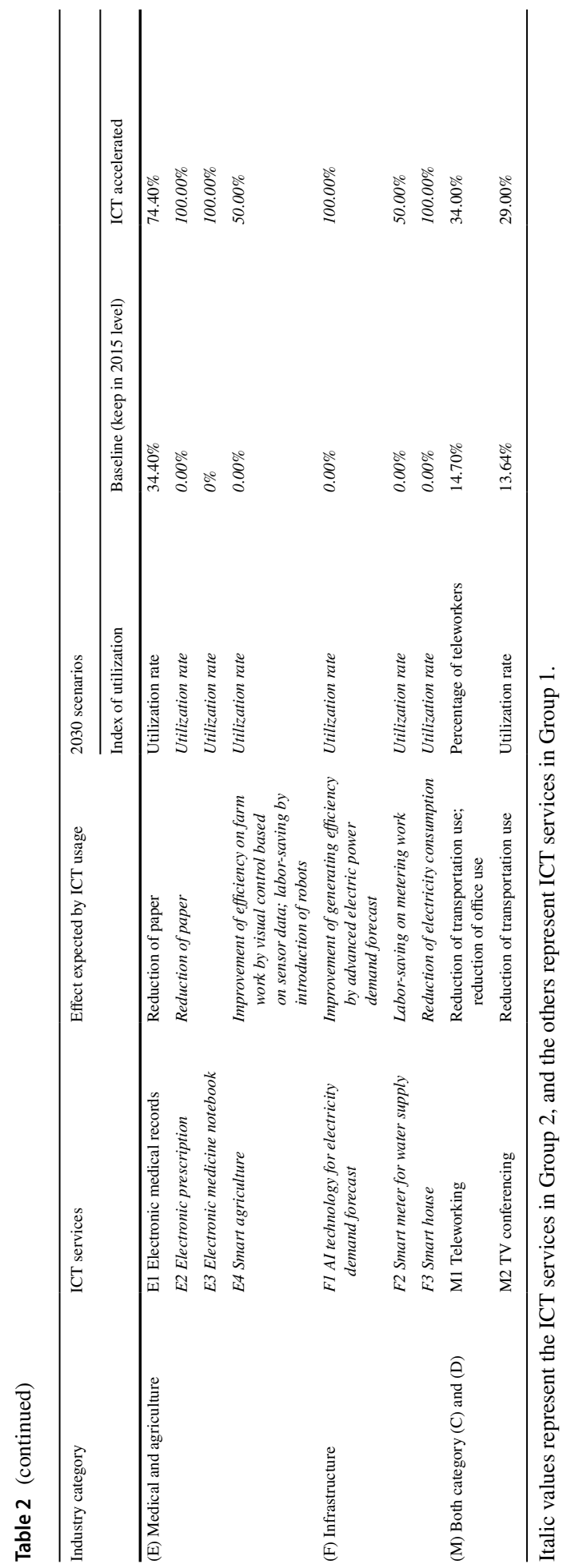


along the increasing trend of past years. For example, the utilization rate of telework is predicted to be $34 \%$ in 2030 in this paper, but, due to the impacts of the COVID-19 Pandemic, the utilization rate of telework in Japan has already reached 28\% in April according to data from 2020 (PERSOL, 2020). Then, for the emerging ICT services in Group 2, our main references are a forecast report on future ICT development in related industries published by Nikkei BP and a forecast report on AI technologies issued by NEDO (NEDO, 2016; Nikkei, 2016). They forecasted the kinds of emerging ICTs that are planned to be implemented in industry sectors and our lives and also the kinds of effects that can be expected by spreading these ICTs. AI technologies are expected to be widely implemented in four fields: manufacturing, mobility, medical/health, and distribution/retail and logistics. Additionally, cashless payment, smart agriculture, smart houses, and smart infrastructure are also highly expected to spread widely. However, since there are no detailed predictions of their utilization rates, the utilization rates of the targeted ICT services in this group are boldly assumed to spread to high levels in our model. Also, another reason is that this paper aims to show the potential impacts of ICT use. For most services in Group 2, utilization rates are assumed to reach $50 \%$ maximum, while for several services considered to spread easily, such as electronic prescriptions and smart houses, utilization rates are assumed to reach $100 \%$. Additionally, the spread of AI technology for distribution is not a strong prospect, since it strongly depends on automated driving.

Investment values to ICT sectors between 2005 and 2020, such as equipment investment or software development, come from a market survey report about the ICT-related market (FCR, 2018), and the values until 2030 are estimated by linear approximation on the basis of the existing data.

\subsection{Power consumption forecast in ICT sector}

To support these future ICT services, a lot of ICT equipment will be needed like sensors for collecting the data, edge computers, data servers, and 5G mobile network equipment. Thus, the increase in power consumption by ICT equipment is a big concern. In this research, the authors also investigated and analyzed power consumption trends of ICT equipment use in the ICT sector in Japan up to 2030 on the basis of data between 2008 and 2018 and related reports on market trend forecasts (e.g., JEITA, 2016). The ICT sector includes fixed/mobile networks, data centers, and end-user devices. To grasp the power consumption trends of the ICT sector itself, the authors attempted to estimate the total power consumption of ICT equipment until 2030 by estimating the changes in the number of each kind of ICT equipment and the changes in the power consumption per unit of each kind of equipment. "Appendix 1.2" shows more details of calculation conditions and data.

According to the three different assumptions on the increased rate of power consumption for each equipment unit per year, the estimation results showed that power consumption of total ICT equipment use in 2030 will increase to 1.2 to 1.5 times that in 2020 (Fig. 3). Since the number of ICT equipment does not change significantly, the change in energy consumption of each ICT equipment will play a decisive role in the total energy consumption in the next 10 years. If it is assumed that the energy consumption of each device increases by $2 \%$ per year, then the ICT total energy consumption in 2030 will be 1.5 times that in 2020. In the CGE model, service demands for ICT in non-ICT are adopted as an indicator to express the energy consumption increases or communication traffic increases in the ICT sector. From the viewpoint of changes in the demand for ICT in each 


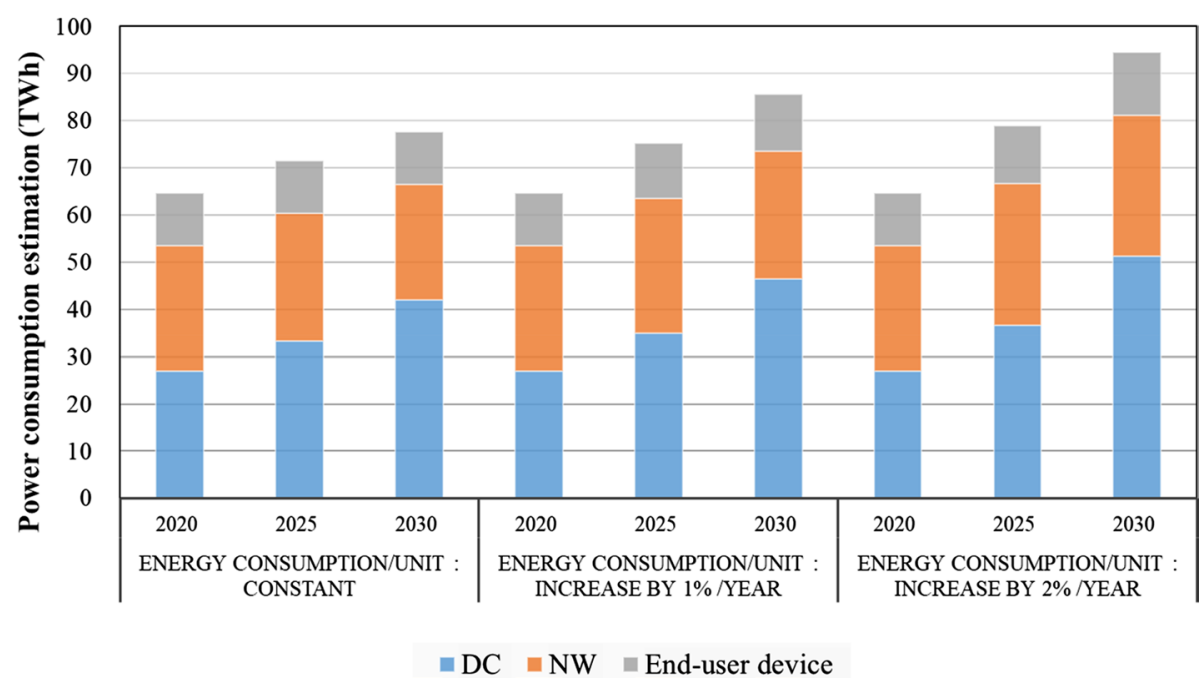

Fig. 3 Estimation results on power consumption of ICT equipment by 2030

sector, including a sensitivity analysis, the input coefficients of telecommunications services in each sector were set to increase up to $1.25,1.50$, and 1.75 times the default values.

\section{Results and discussion}

\subsection{Results in each scenario}

There are two scenarios set in this research: baseline, in which all technologies maintain the level of 2015 until 2030, and ICT accelerated, in which only ICT technologies accelerate in accordance with our forecast. In the ICT accelerated scenario, to give a sensitivity analysis of service demand increase for the ICT sector, the model simulated four cases: ICT_1.00, ICT_1.25, ICT_1.50, and ICT_1.75. That means service demand for the ICT sector from non-ICT sectors in 2030 is assumed to be 1.00 (the same as that in 2015), 1.25, 1.50 , and 1.75 times that in 2015 .

First, Fig. 4 shows increases in GDP in each scenario. Since the pre-condition of GDP growth is assumed as $1.7 \%$ per year, in the baseline scenario, GDP will increase to about $¥ 700$ trillion in 2030. In ICT_1.00, where ICT is introduced without any additional ICT service inputs, GDP increases $1.9 \%$ more, $¥ 13$ trillion, compared with the baseline scenario. In addition, in ICT_1.25, ICT_1.50, and ICT_1.75, where the service demand for the ICT sector increases by $1.25,1.50$, and 1.75 times, GDP increases by $1.5 \% 1.3 \%$, and $1.1 \%$, respectively, compared with the baseline. Compared with the case where the increase in service demand for ICT is not taken into consideration, GDP growth tends to slow down. Nevertheless, an increase of $1 \%$ or more can be expected.

For more details, Fig. 5 shows the production amounts by sectors in 2030 in two cases, ICT_1.00 and ICT_1.75 in the ICT accelerated scenario, where the production amounts by sector in the baseline in 2030 are assumed to be 1. Compared with the baseline scenario, in each case of the ICT accelerated scenario, with the spread of ICT, the activities of the information and communication sector and information and communication electronics 


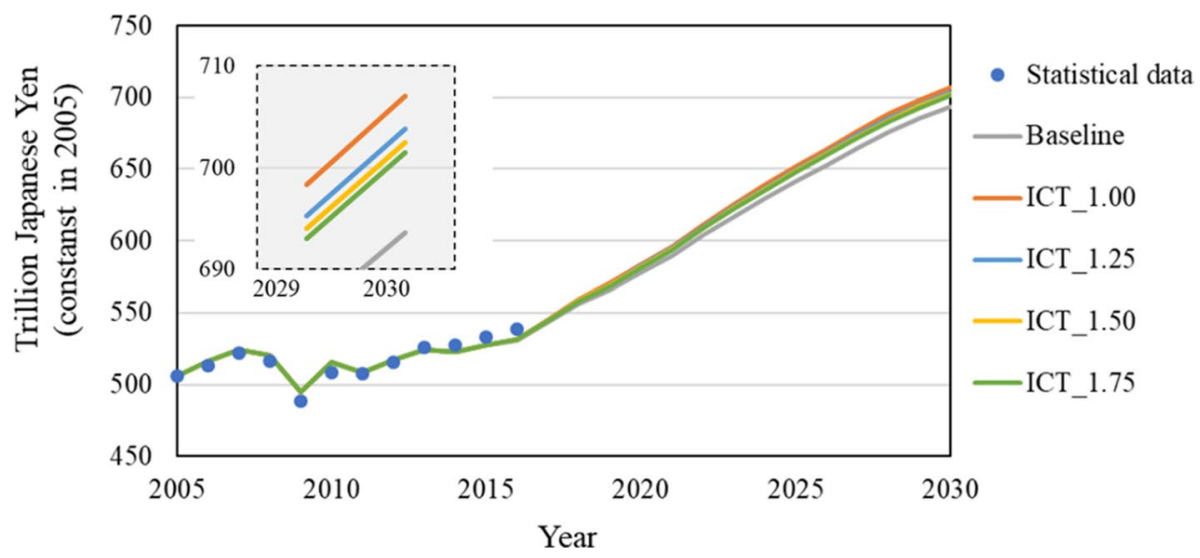

Fig. 4 GDP during 2005 to 2030 in each scenario

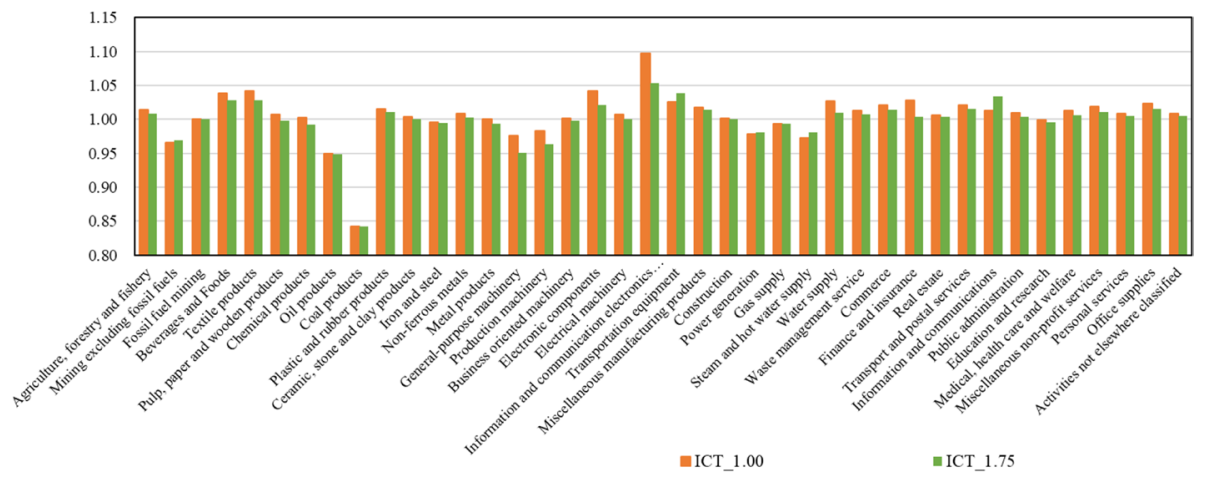

Fig. 5 Production amounts by sector in two cases in 2030 (value in the baseline in 2030=1)

equipment sector will increase. Then, focusing on most service sectors, activities become more dynamic due to production efficiency improvements by ICT introduction, especially due to labor-saving and better matching between supply and demand. Also, as the total GDP grows, so do income levels of households. Then, activities directly related to final consumption will increase relatively easily. As a result, the activities in most service sectors will tend to slightly increase. On the other hand, there are slight decreases in mining, general-purpose machinery, production machinery, and power generation, and significant decreases in oil products and coal products. The decreases in oil products and coal products are due to more efficient logistics and decreased inputs in many production sectors.

Then, regarding GHG emissions, as shown in Fig. 6, GHG emissions decrease from $1400 \mathrm{MtCO}_{2}$ eq in 2005 to $1150 \mathrm{MtCO}_{2}$ eq in 2030 even in the baseline scenario, as a result of modifying the power supply configuration by the government plan in NDC (MOFA, 2015). Then, in the ICT accelerated scenario, GHG emissions are reduced by $4.7 \%$ in 2030 in the ICT_1.00 case compared with the baseline. In addition, in ICT_1.25, ICT_1.50, and ICT_1.75 where service demand for the ICT sector increases by $1.25,1.50$, and 1.75 times, GHG emissions are reduced by $4.8 \%, 4.8 \%$, and $4.47 \%$, respectively, compared with the baseline. GHG emissions do not significantly change compared with GDP because the 


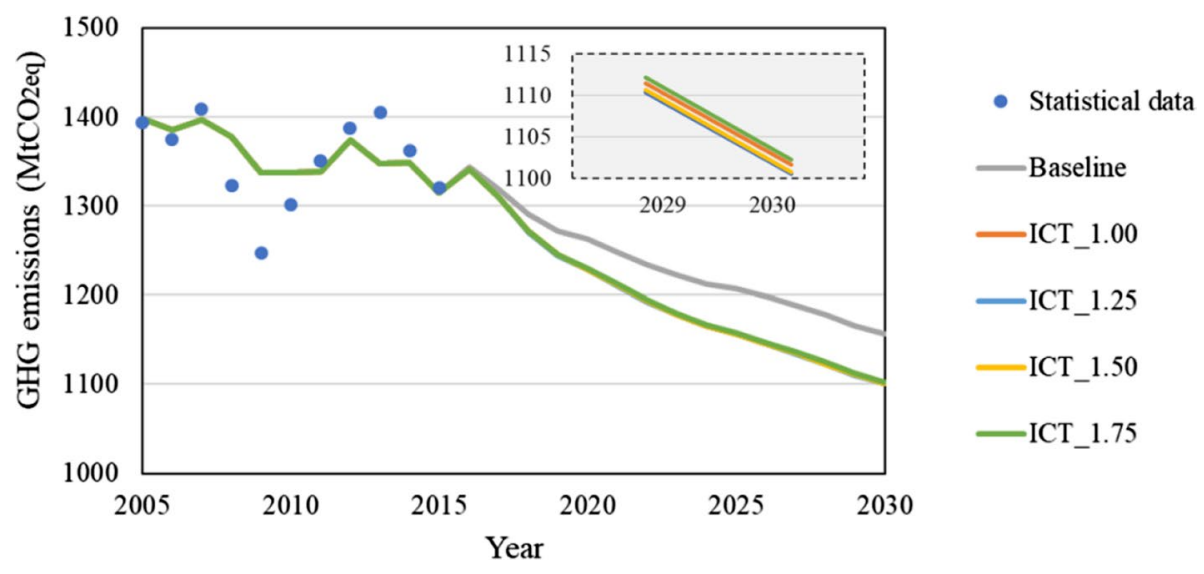

Fig. 6 GHG emissions estimation from 2005 to 2030 in each scenario (unit: $\mathrm{MtCO}_{2 \mathrm{eq}}$ )

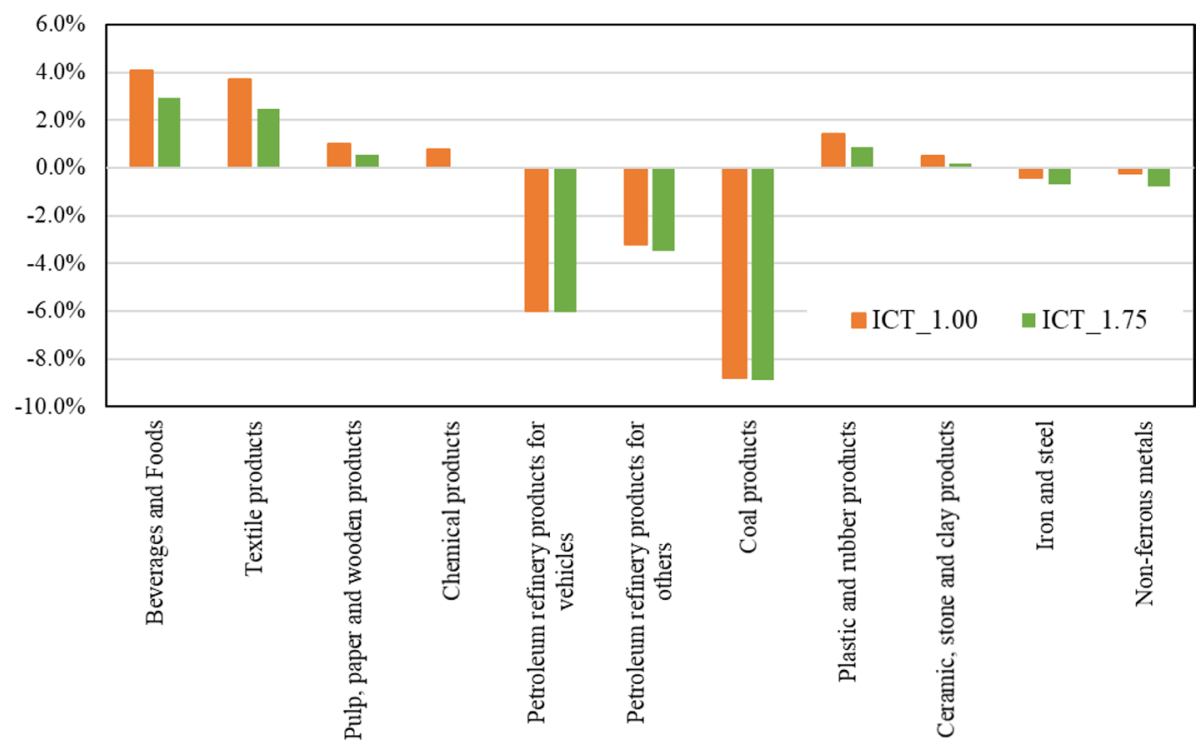

Fig. 7 Changes in the demand of materials in 2030 (value in baseline scenario $=1$ )

power consumption of the ICT sector is a relatively small part of total power consumption in Japan, and the increase in demand for ICT services may affect other inputs and offset them. This means that even when the increase in future power consumption of ICT equipment use is considered in this model, total GHG emissions in 2030 will also be reduced through ICT service usage. For more details, Appendix 1.1 shows the changes in GHG emissions in each sector.Lastly, this paper also briefly analyzes the changes in the demand for materials. If production activities become more efficient due to the advances in ICT services, the amount of materials unnecessarily consumed until now will possibly be saved. Therefore, analyzing the materials will clarify such indirect effects. Figure 7 shows the 
changes in the demand for each material in 2030 in the ICT accelerated scenario compared with the baseline. The material commodities are shown in shaded cells in Appendix 1.1. Since introducing ICT services will improve the efficiency of logistics and energy saving, the demand for fossil fuels will be greatly reduced. The demand for steel and nonferrous metals will slightly decrease, which also means that the increased use of ICT will not increase metal consumption. In contrast, demand for food and beverage products and textile products directly related to final consumption will increase over $2 \%$, while demands for others will mostly increase less than $1 \%$.

\subsection{Discussion}

The results showed that though the spread of ICT will increase the power demand of the ICT sector itself, it will contribute much more to reducing energy demand in other sectors. Total GHG emissions in Japan in 2030 can be reduced up to about $4.8 \%$, with over $1 \%$ additional GDP growth, compared with the baseline scenario.

However, this research contains some uncertainties. For example, first, the most basic preconditions in this research are based on the forecast reports in Japan's Intended Nationally Determined Contribution (INDC) submitted in 2015 (MOFA, 2015), since such macroeconomic data are not updated frequently. The assumed GDP growth rate may be higher than in reality. Second, due to the COVID-19 Pandemic, the world is likely to change significantly in the future. In particular, the COVID-19 Pandemic has triggered a major advance in ICT throughout the world. In Japan, for example, the telework utilization rate is now much higher than in 2019 (Okubo, 2020). Also, the uses of electronic cash (EC) and cashless payment are also increasing rapidly. Furthermore, ICT is expected to drastically spread in areas such as online education and online medical care, which have not been evaluated this time (because their current utilization rates are low). As a result, the GHG reduction effect may be even greater than in the current calculation results in this research. Third, on the other hand, the ICT skill level in the workforce will also affect the speed of ICT popularization. The shortage of personnel sufficiently skilled in cutting-edge technologies is even being felt in Silicon Valley (Metz, 2017), so this shortage is another concern that should be considered.

A scenario analysis like this study aims to show potential future scenarios rather than predict the future correctly and to present ways to move toward a more desirable future. In that sense, more scenario settings may need to be studied in future works, taking into account the above concerns.

\subsection{Future issues}

Several technical issues are also considered for our future works. First, although the model reflected the increase in additional energy consumption due to ICT introduction, it needs to be further refined in the future because the ratio is set uniformly for all sectors. Second, naturally, in addition to the introduction of such ICT services, the introduction of various advanced technologies such as energy-saving techniques in other sectors and the expansion of renewable energy should also be considered at the same time. However, to clarify the impacts of ICT introduction, in this research, only the acceleration of the ICT level is considered. GHG emissions may decline further considering technological progress in areas other than ICT. 
Furthermore, from an environmental aspect, excluding GHG emissions and resource consumption discussed in this research, ICT use may have a wider footprint including pollution associated with mining rare metals, exploiting water resources, and generating electronic waste leading to further pollution of ecosystems. This research focused on the GHG emissions caused by ICT usage and demand for raw materials, since these two factors are our biggest concerns currently. However, other issues are also important for us and are expected to be further researched.

\subsection{Values and limitations}

With concern regarding increasing ICT traffic globally, this research provided a method to evaluate the future overall impacts of ICT introduction by considering both the increase in energy consumption of ICT equipment itself and corresponding reduction of environmental impact in other sectors. This method can help us analyze whether a given scenario of ICT use will contribute to the realization of a sustainable society. Further, this method can also help us to think out more sustainable ways to use ICT by extending scenarios that are more environmentally and economically friendly and identifying latent problems in ICT development. The results of this research are based solely on the ICT utilization in Japan. The use of ICT and the speed of ICT development, especially the direct effects of ICT use shown in Table 2, may not be the same in each country. Researchers can use this method to evaluate the impacts of ICT use in their own countries on the basis of their countries' own data.

\section{Conclusion}

Although the rapid spread of information and communications technology (ICT) promotes economic growth and makes daily life more convenient, there is a big concern that ICT equipment use will increase energy consumption. This research adopted a dynamic computable general equilibrium (CGE) model to analyze the future environmental and economic impacts until 2030 brought about by popularization of 36 kinds of ICT services, considering both positive effects of ICT use in non-ICT sectors and negative effects caused by ICT equipment's operation in the ICT sector. 
The model results showed that besides the development of ICT-related sectors, the spread of ICT services, especially some artificial intelligence (AI)-based services, can improve productivity through labor-saving and better matching of supply and demand and contribute to increasing overall GDP. Then, regarding the above concern of the increased energy consumption of ICT equipment, the model results also showed that total greenhouse gas (GHG) emissions will not greatly increase, since the power consumption of ICT services is a relatively small part of overall power consumption, and the increase in service demand for ICT may affect other inputs and offset them. Particularly, efficiency of logistics and manufacturing can greatly reduce the input of oil and coal products, thereby drastically reducing GHG emissions. At the same time, most material demands also decreased on different levels due to the dematerialization brought about by ICT usage. In 2030, compared with the baseline scenario, at least $1 \%$ additional GDP growth and 4\% GHG emission reduction can be expected by introducing targeted ICT in the ICT accelerated scenario, which also means the feasibility of decoupling the economic and environmental effects of ICT use.

In the future, ICT will surely be more widespread than described here. There are great expectations for digital transformation and automation technologies for agriculture, manufacturing, and service industries. Breakthroughs in productivity by ICT will enable fewer inputs including raw materials and energy and more production and thereby drive greater economic development and environment load reduction. During and after the COVID-19 Pandemic, ICT should help us to achieve an economic recovery without rebounding GHG emissions and build a sustainable society in the next few decades.

\section{Appendix 1 Details on the CGE model structure and detailed results}

This appendix presents details on the CGE model's structure and estimated results. Table 3 shows the sector classification in the model, while Figs. 8 and 9 show the nest structure of production activities and final consumption. The key formulas of the model are shown in Table4. Table 5 details the results of GDP and GHG emissions from 2005 to 2030, and Fig. 10 shows GHG emission changes in each sector in the ICT accelerated scenario compared with the baseline scenario in 2030 . 
Table 3 Sectors and commodities in this model

\begin{tabular}{|c|c|c|c|}
\hline \multicolumn{2}{|c|}{ Sector } & \multicolumn{2}{|c|}{ Commodity } \\
\hline 01 & Agriculture, forestry and fishery & 01 & Agriculture, forestry and fishery \\
\hline 02 & Mining excluding fossil fuels & 02 & Mining excluding fossil fuels \\
\hline 03 & Fossil fuel mining & $03 \mathrm{c}$ & Coal mining \\
\hline & & 03 o & Crude petroleum \\
\hline & & $03 \mathrm{~g}$ & Natural gas \\
\hline 04 & Beverages and Foods & 04 & Beverages and Foods \\
\hline 05 & Textile products & 05 & Textile products \\
\hline 06 & Pulp, paper and wooden products & 06 & Pulp, paper and wooden products \\
\hline 07 & Chemical products & 07 & Chemical products \\
\hline 08 & Oil products & $08 \mathrm{~m}$ & Petroleum refinery products for vehicles \\
\hline & & 080 & Petroleum refinery products for others \\
\hline 09 & Coal products & 09 & Coal products \\
\hline 10 & Plastic and rubber products & 10 & Plastic and rubber products \\
\hline 11 & Ceramic, stone and clay products & 11 & Ceramic, stone, and clay products \\
\hline 12 & Iron and steel & 12 & Iron and steel \\
\hline 13 & Non-ferrous metals & 13 & Non-ferrous metals \\
\hline 14 & Metal products & 14 & Metal products \\
\hline 15 & General-purpose machinery & 15 & General-purpose machinery \\
\hline 16 & Production machinery & 16 & Production machinery \\
\hline 17 & Business-oriented machinery & 17 & Business-oriented machinery \\
\hline 18 & Electronic components & 18 & Electronic components \\
\hline 19 & Electrical machinery & 19 & Electrical machinery \\
\hline 20 & $\begin{array}{l}\text { Information and communication electron- } \\
\text { ics equipment }\end{array}$ & 20 & $\begin{array}{l}\text { Information and communication elec- } \\
\text { tronics equipment }\end{array}$ \\
\hline 21 & Transportation equipment & 21 & Transportation equipment \\
\hline 22 & Miscellaneous manufacturing products & 22 & Miscellaneous manufacturing products \\
\hline 23 & Construction & 23 & Construction \\
\hline 24 & Private power generation & 24 & Electricity \\
\hline $24 n$ & Nuclear & & \\
\hline $24 \mathrm{tc}$ & Coal thermal power & & \\
\hline 24to & Oil thermal power & & \\
\hline $24 \operatorname{tg}$ & Gas thermal power & & \\
\hline $24 \mathrm{~h}$ & Hydro & & \\
\hline $24 \mathrm{~s}$ & PV & & \\
\hline $24 w$ & Wind & & \\
\hline $24 \mathrm{~g}$ & Geothermal & & \\
\hline $24 b$ & Biomass & & \\
\hline 25 & Gas supply & 25 & Gas supply \\
\hline 26 & Steam and hot water supply & 26 & Steam and hot water supply \\
\hline 27 & Water supply & 27 & Water supply \\
\hline 28 & Waste management service & 28 & Waste management service \\
\hline 29 & Commerce & 29 & Commerce \\
\hline 30 & Finance and insurance & 30 & Finance and insurance \\
\hline 31 & Real estate & 31 & Real estate \\
\hline 32 & Transport and postal services & 32 & Transport and postal services \\
\hline
\end{tabular}


Table 3 (continued)

\begin{tabular}{llll}
\hline Sector & & \multicolumn{2}{l}{ Commodity } \\
\hline 33 & Information and communications & 33 & Information and communications \\
34 & Public administration & 34 & Public administration \\
35 & Education and research & 35 & Education and research \\
36 & Medical, health care, and welfare & 36 & Medical, health care, and welfare \\
37 & Miscellaneous non-profit services & 37 & Miscellaneous non-profit services \\
38 & Personal services & 38 & Personal services \\
39 & Office supplies & 39 & Office supplies \\
40 & Activities not elsewhere classified & 40 & Activities not elsewhere classified
\end{tabular}

The italic values show material commodities

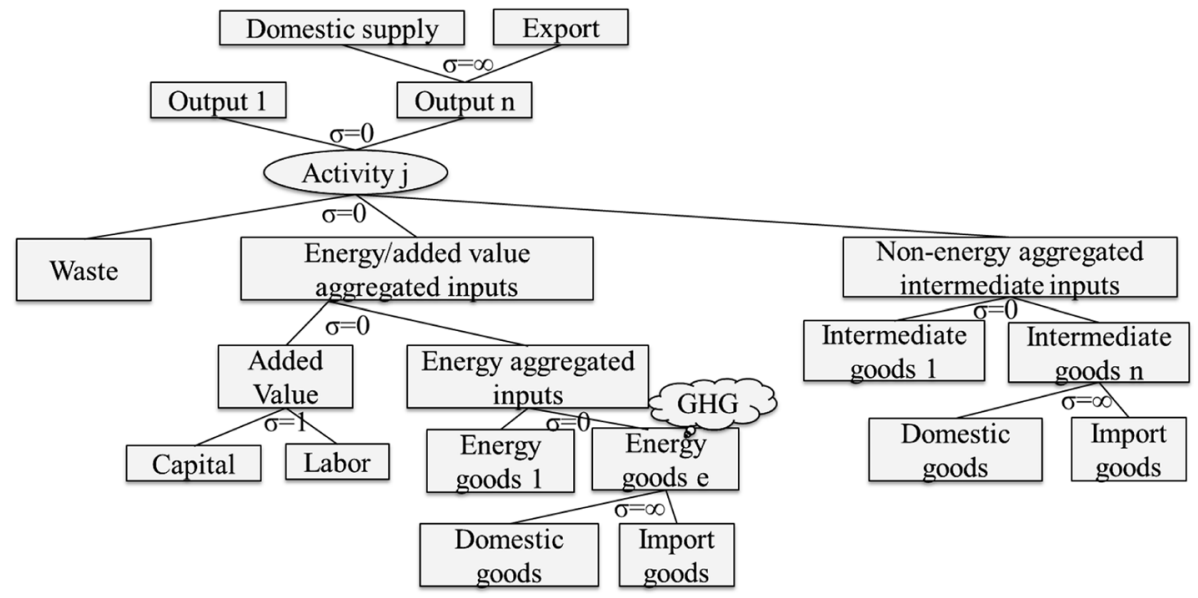

Fig. 8 Structure of production activities

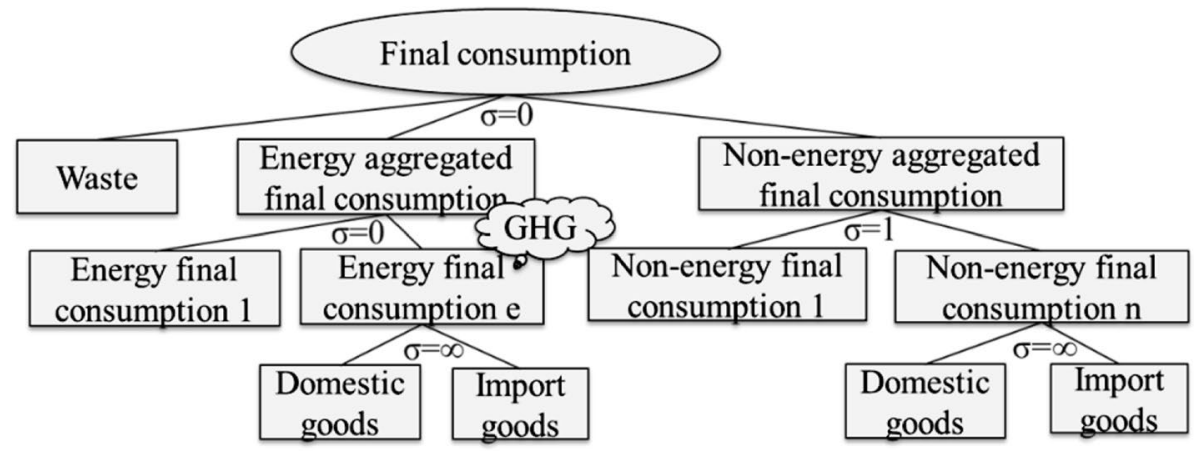

Fig. 9 Structure of final consumption 
Table 4 Key formulas used in the model

Blocks Key formulas

Production sectors

$$
\sum_{i=1}^{43} P_{i} X_{i j}+P_{K} K_{j}+P_{L} L_{j}=\sum_{i=1}^{43} P_{i} Y_{i j}
$$

Household sector

$$
\begin{aligned}
& H=P_{K} \sum_{j=1}^{49} K_{j}+P_{L} \sum_{j=1}^{49} L_{j} \\
& H=\sum_{i=1}^{43} P_{i}\left(C_{i}+\sum_{j=1}^{49} I_{i j}\right) \\
& K_{j, t+1}=\left(1-\delta_{j}\right) K_{j, t}+\sum_{i=1}^{43} I_{i j}
\end{aligned}
$$

Market equilibrium

$$
\begin{aligned}
& P_{i}\left\{\sum_{j=1}^{49} Y_{j i}-\left(\sum_{j=1}^{49} X_{i j}+C_{i}+\sum_{j=1}^{49} I_{i j}\right)\right\}=0 \\
& P_{i} \geq 0 \text { and } \sum_{j=1}^{49} Y_{j i}-\left(\sum_{j=1}^{49} X_{i j}+C_{i}+\sum_{j=1}^{49} I_{i j}\right) \geq 0 \\
& P_{K}\left\{K^{*}-\sum_{j=1}^{49} K_{j}\right\}=0, P_{K} \geq 0 \text { and } K^{*}-\sum_{j=1}^{49} K_{j} \geq 0 \\
& P_{L}\left\{L^{*}-\sum_{j=1}^{49} L_{j}\right\}=0, P_{L} \geq 0 \text { and } L^{*}-\sum_{j=1}^{49} L_{j} \geq 0
\end{aligned}
$$

$P$ : price, $X$ : intermediate inputs, $Y$ : output, $K$ : capital, $L$ : labor, $H$ : income (expenditure), $K^{*}:$ capital endowment, $L^{*}$ : labor endowment, $C$ : final consumption, $I$ : investment, $i$ : commodities, $j$ : sector, $\delta$ : depreciation rate 
Table 5 Detailed results of GDP and GHG emissions from 2005 to 2030

\begin{tabular}{|c|c|c|c|c|c|c|c|c|}
\hline \multirow[t]{2}{*}{ Year } & \multicolumn{4}{|c|}{ GDP (Trillion Japanese Yen) (constanst 2005) } & \multicolumn{4}{|c|}{ GHG emission (MtCO2eq) } \\
\hline & Statistic data & Baseline & ICT_1.00 & ICT_1.75 & Statistic data & Baseline & ICT_1.00 & ICT_1.75 \\
\hline 2005 & 506.1 & 506.1 & 506.1 & 506.1 & 1393.3 & 1397.6 & 1397.6 & 1397.6 \\
\hline 2006 & 513.3 & 516.4 & 516.4 & 516.4 & 1374.3 & 1386.1 & 1386.1 & 1386.1 \\
\hline 2007 & 521.8 & 524.6 & 524.6 & 524.6 & 1409.2 & 1397.0 & 1397.0 & 1397.0 \\
\hline 2008 & 516.1 & 520.5 & 520.5 & 520.5 & 1323.5 & 1377.7 & 1377.7 & 1377.7 \\
\hline 2009 & 488.1 & 495.1 & 495.1 & 495.1 & 1247.6 & 1337.0 & 1337.0 & 1337.0 \\
\hline 2010 & 508.6 & 515.9 & 515.9 & 515.9 & 1301.4 & 1338.0 & 1338.0 & 1338.0 \\
\hline 2011 & 508.0 & 508.5 & 508.5 & 508.5 & 1351.1 & 1338.4 & 1338.4 & 1338.4 \\
\hline 2012 & 515.6 & 517.4 & 517.4 & 517.4 & 1386.9 & 1373.8 & 1373.8 & 1373.8 \\
\hline 2013 & 525.9 & 524.7 & 524.7 & 524.7 & 1404.6 & 1347.9 & 1347.9 & 1347.9 \\
\hline 2014 & 527.7 & 522.5 & 522.5 & 522.5 & 1361.5 & 1348.3 & 1348.3 & 1348.3 \\
\hline 2015 & 533.5 & 527.8 & 527.8 & 527.8 & 1320.9 & 1314.7 & 1314.7 & 1314.7 \\
\hline 2016 & 539.0 & 530.9 & 531.4 & 531.2 & & 1344.0 & 1341.5 & 1341.3 \\
\hline 2017 & & 543.4 & 545.0 & 544.4 & & 1319.1 & 1309.6 & 1309.6 \\
\hline 2018 & & 556.4 & 559.4 & 558.2 & & 1291.2 & 1271.3 & 1272.0 \\
\hline 2019 & & 566.0 & 570.3 & 568.6 & & 1272.3 & 1245.1 & 1245.7 \\
\hline 2020 & & 577.9 & 583.3 & 581.1 & & 1262.4 & 1228.6 & 1229.8 \\
\hline 2021 & & 590.0 & 596.5 & 593.9 & & 1247.4 & 1210.6 & 1211.9 \\
\hline 2022 & & 604.1 & 611.7 & 608.6 & & 1233.5 & 1193.1 & 1194.3 \\
\hline 2023 & & 617.1 & 625.7 & 622.2 & & 1222.8 & 1178.4 & 1179.6 \\
\hline 2024 & & 629.6 & 639.1 & 635.2 & & 1212.4 & 1165.7 & 1167.0 \\
\hline 2025 & & 641.6 & 651.9 & 647.7 & & 1207.6 & 1157.1 & 1158.2 \\
\hline 2026 & & 653.2 & 664.2 & 659.7 & & 1198.1 & 1145.8 & 1146.9 \\
\hline 2027 & & 664.8 & 676.6 & 671.7 & & 1189.0 & 1135.4 & 1136.4 \\
\hline 2028 & & 675.9 & 688.3 & 683.1 & & 1178.0 & 1123.9 & 1124.7 \\
\hline 2029 & & 685.4 & 698.3 & 693.0 & & 1165.7 & 1111.4 & 1112.2 \\
\hline 2030 & & 693.6 & 707.0 & 701.4 & & 1156.3 & 1101.6 & 1102.2 \\
\hline
\end{tabular}

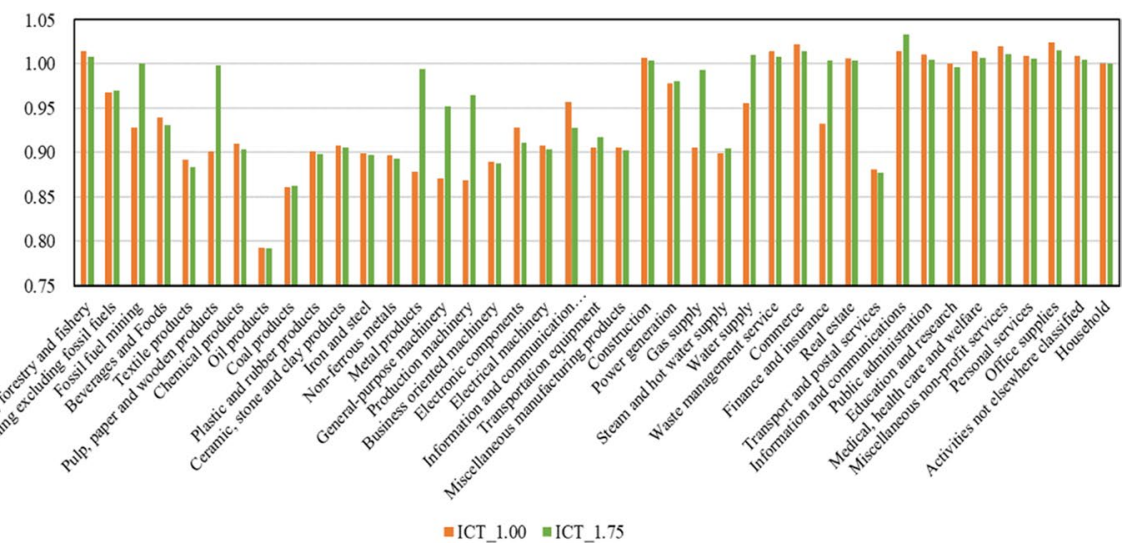

Fig. 10 GHG emissions from each sector in ICT accelerated scenario in 2030 


\section{Appendix 2 Details on the future estimation on energy consumption of ICT sector}

This appendix details the calculation conditions and data used in estimating the power consumption of ICT-related equipment until 2030.

The same as worldwide, total communication traffic on broadband in Japan also increased significantly (Fig. 11) [MICa, 2019]. However, the exponential increase in power consumption of ICT equipment has been constrained by various types of technological progress, such as the increase in the integration rate of semiconductors in accordance with Moore's law and improvement in power supply efficiency. As an example for servers, Fig. 12 shows the past trends in total power consumption and number of servers based on shipping statistics from the Japan Electronics and Information Technology Industries

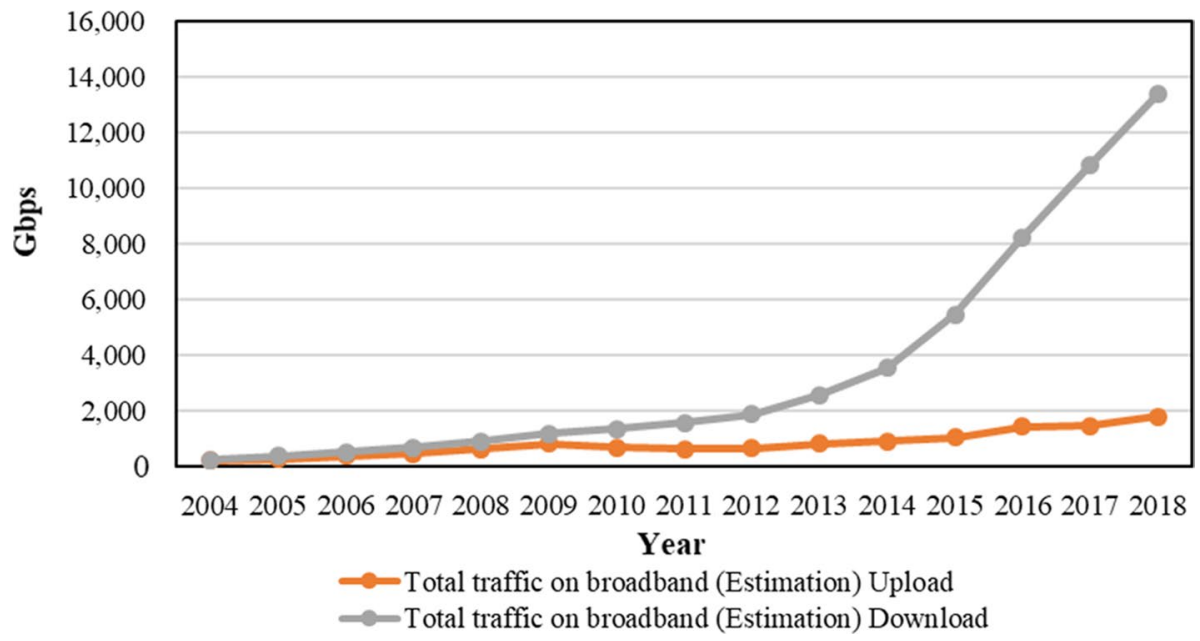

Fig. 11 Past communication traffic trends in Japan

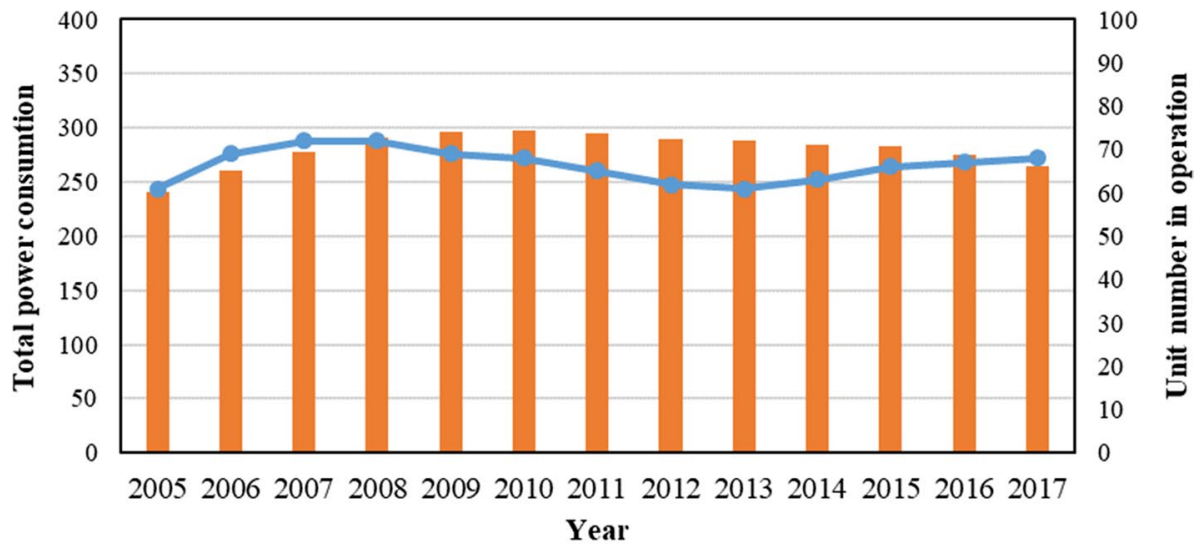

Unit number in operation( $10^{\wedge} 4$ unit) $\quad-$ Total power consumption $\left(10^{\wedge} 10 \mathrm{KWh}\right)$

Fig. 12 Total power consumption and unit number of servers 
Association (JEITA). Neither the total number nor power consumption of servers increased much [JEITA, 2016], which means that rated power for each server remained roughly flat.

To catch the change trends of power consumption of ICT equipment itself, we attempted to estimate the total power consumption of ICT equipment until 2030 by estimating the changes in the number of each kind of equipment and the power consumption per unit.

Regarding the former, the change in the number of each kind of equipment by 2030 was estimated on the basis of two kinds of information. One is an investigation into the number of ICT equipment between 2008 and 2018. The other is forecast information for the next 10 years, such as the commercialization of $5 \mathrm{G}$ or spread of edge computers. ICT equipment is classified into three sub-sectors: network equipment, data center equipment, and end-user devices. Table 6 lists the main ICT equipment considered in this research. The main data source is the statistics in the Preliminary Report on Indices of Industrial Production from the Ministry of Economy, Trade and Industry (METI, 2019). For some kinds of equipment, statistics for imported goods come from the Communication and Information Network Association of Japan (CIAJ, 2018). The numbers of units in operation were estimated from the numbers of shipments each year, taking into account the useful lifetime of each equipment. The main change trends for the next 10 years considered in this estimation include the following:

Table 6 Main ICT equipment included in this estimation

\begin{tabular}{|c|c|c|}
\hline \multicolumn{2}{|l|}{ Intended use } & $\begin{array}{l}\text { Equipment type } \\
\text { General-purpose computers (main frame) }\end{array}$ \\
\hline DC & Server & $\begin{array}{l}\text { General-purpose computers (main frame) } \\
\text { Midrange computers } \\
\text { Personal computers for server use } \\
\text { External storages } \\
\text { Miscellaneous external storages }\end{array}$ \\
\hline NW & Network equipment & $\begin{array}{l}\text { Digital transmission equipment } \\
\text { Network connection devices } \\
\text { Base station communication devices }\end{array}$ \\
\hline \multirow[t]{4}{*}{ End-user device } & Communication equipment & $\begin{array}{l}\text { Telephones } \\
\text { Facsimiles } \\
\text { Mobile phones } \\
\text { Public telephones }\end{array}$ \\
\hline & $\mathrm{PC}$ & $\begin{array}{l}\text { Desktop personal computers } \\
\text { Laptop computers }\end{array}$ \\
\hline & Information terminal & $\begin{array}{l}\text { Automatic teller machine } \\
\text { Other banking terminals } \\
\text { Kiosk terminals } \\
\text { Handy terminals } \\
\text { Other terminal units }\end{array}$ \\
\hline & IoT & $\begin{array}{l}\text { Telemeter/telecontrol } \\
\text { Detector, transducer, and transmitters } \\
\text { Distributed control systems } \\
\text { Miscellaneous monitoring and control system } \\
\text { Monitoring instruments for environmental quality }\end{array}$ \\
\hline
\end{tabular}


- Servers are expected to increase production to meet cloud and edge computing demands.

- Data centers are projected to grow at an annual rate of 14.4\% until 2024 (MIC 2018), so servers are also expected to grow at the same rate.

- Digital transmission equipment and network connection equipment peaked in 2014 with the transition to new nodes of telecommunication carriers, and production volume is currently declining. Thus, the equipment will peak in 2025 in line with the transition from the PSTN to IP systems (NTT, 2010).

- Changes in smartphone utilization are assumed to fluctuate almost in proportion to changes in the population.

- Laptop utilization is projected to remain flat.

- Other information terminals such as IoT will grow at an annual rate of $5 \%$ (MICb, 2019).

Then, regarding the latter, the energy-saving performance of many devices has improved in recent years. As an example, as shown in Fig. 12, even though each server was processing more information, it did not consume more power. However, there is not enough detailed data on the changes in the power consumption per unit of all kinds of ICT equipment. In this research, as a sensitivity analysis, three kinds of assumption are set. One is power consumption per unit does not change until 2030. The second is it will increase by $1 \%$ per year from 2020 to 2030 . The third is it will increase by $2 \%$ per year from 2020 to 2030. Estimation results are shown in Fig. 3 in Sect. 3.4. Power consumption of total ICT equipment in 2030 will increase by 1.2 to 1.5 times that in 2020 under the three assumptions.

Compared with the forecasts in other research, ITU-T reported power consumption of the global ICT sector in 2030 will increase to 1.3 times that in 2015 [L.1470, 2020]. Then, according to the estimation by the Green IT Promotion Council, energy consumption of ICT equipment in Japan in 2030 will increase to about 2 times that in 2020 [JEITA, 2013]. Therefore, a 1 to 2 times increase in power consumption of ICT equipment from 2015 to 2030 can be considered reasonable.

Author contributions All authors contributed to the study conception and design. Material preparation, data collection, model simulation, and analysis were performed by [XZ], [TM], and [MS]. The first draft of the manuscript was written by $[\mathrm{XZ}]$, and all authors commented on previous versions of the manuscript. All authors read and approved the final manuscript.

Funding None.

Data availability The datasets during and/or analyzed during the current study are available from the corresponding author on reasonable request.

\section{Declarations}

Conflicts of interest The authors declare that they have no competing interests.

Open Access This article is licensed under a Creative Commons Attribution 4.0 International License, which permits use, sharing, adaptation, distribution and reproduction in any medium or format, as long as you give appropriate credit to the original author(s) and the source, provide a link to the Creative Commons licence, and indicate if changes were made. The images or other third party material in this article are included in the article's Creative Commons licence, unless indicated otherwise in a credit line to the material. If material is not included in the article's Creative Commons licence and your intended use is not 
permitted by statutory regulation or exceeds the permitted use, you will need to obtain permission directly from the copyright holder. To view a copy of this licence, visit http://creativecommons.org/licenses/by/4.0/.

\section{References}

Andrae, A. S. G., \& Edler, T. (2015). On global electricity usage of communication technology: Trends to 2030. Challenges, 6, 117-157. https://doi.org/10.3390/challe6010117

Barnett, Jr, T., Jain, S., Andra, U., Khurana, T. (2018). Cisco visual networking index (VNI) - Complete forecast update. 2017-2022. Retrieved 5 March 2021, from https://www.cisco.com/c/dam/m/en_us/ network-intelligence/service-provider/digital-transformation/knowledge-network-webinars/pdfs/1213business-services-ckn.pdf

Bastida, L., Cohen, J. J., Kollmann, A., Moya, A., \& Reichl, J. (2019). Exploring the role of ICT on household behavioural energy efficiency to mitigate global warming. Renewable and Sustainable Energy Reviews, 103, 455-462. https://doi.org/10.1016/j.rser.2019.01.004

Bieser, J., \& Hilty, L. M. (2018). Indirect effects of the digital transformation on the environmental sustainability: methodological challenges in assessing the greenhouse gas abatement potential of ICT. EPiC Series in Computing, 52, 68-81.

Bomhof, F., van Hoorik, P., \& Donkers, M. (2009). Systematic analysis of rebound effects for greening by ICT' initiatives. Communications \& Strategies, 76, 77-96.

Boonpanya, T., \& Masui, T. (2021). Assessing the economic and environmental impact of freight transport sectors in Thailand using computable general equilibrium model. Journal of Cleaner Production, 280(1), 124271. https://doi.org/10.1016/j.jclepro.2020.124271

Chunark, P., Limmeechokchai, B., Fujimori, S., \& Masui, T. (2017). Renewable energy achievements in $\mathrm{CO}_{2}$ mitigation in Thailand's NDCs. Renewable Energy, 114, 1294-1305. https://doi.org/10.1016/j. renene.2017.08.017

CIAJ (Communications and Information network Association of Japan). (2018). Mid-term demand forecast for telecommunication equipment. CIAJ. (In Japanese)

Erdmann, L., \& Hilty, L. M. (2010). Scenario analysis: Exploring the macroeconomic impacts of information and communication technologies on greenhouse gas emissions. Journal of Industrial Ecology. https://doi.org/10.1111/j.1530-9290.2010.00277.x

FCR (Fuji Chimera Research \& Institute Inc.). (2018). Study of new business strategies by SI/NI vendors of Japan. FCR. (In Japanese)

Galvin, R. (2015). The ICT/electronics question: Structural change and the rebound effect. Ecological Economics, 120, 23-31. https://doi.org/10.1016/j.ecolecon.2015.08.020

GeSI (Global e-Sustainability Initiative). (2015) SMARTer2030-ICT solutions for 21st century challenges. Retrieved March 5, 2021 from http://smarter2030.gesi.org/

GIO (Greenhouse Gas Inventory Office of Japan), CGER, NIES. (2019). National greenhouse gas inventory report of Japan. Retrieved March 5, 2021, from https://www.env.go.jp/earth/ondanka/ghg-mrv/unfccc/ NIR-JPN-2019-v3.0.pdf

Google (2019) Google environmental report. Retrieved March 5, 2021, from https://sustainability.google/ reports/environmental-report-2019/\#data-centers

Gossart, C. (2015). Rebound effects and ICT: a review of the literature. In L. M. Hilty \& B. Aebischer (Eds.), ICT innovations sustainability (pp. 439-444). Springer.

L.1470. (2020). Greenhouse gas emissions trajectories for the information and communication technology sector compatible with the UNFCCC Paris Agreement. International Telecommunication Union

Hilty, L. M., \& Aebischer, B. (2014). ICT innovations for sustainability: An emerging research field. In L. M. Hilty \& B. Aebischer (Eds.), ICT innovations for sustainability (pp. 3-36). Springer. https://doi. org/10.1007/978-3-319-09228-7_1

IPCC. (2014). AR5 synthesis report: Climate change 2014. Retrieved March 5, 2021, from https://www. ipcc.ch/assessment-report/ar5/

James Joyce, P., Finnveden, G., Håkansson, C., \& Wood, R. (2019). A multi-impact analysis of changing ICT consumption patterns for Sweden and the EU: indirect rebound effects and evidence of decoupling. Journal of Cleaner Production, 211, 1154-1161. https://doi.org/10.1016/j.jclepro.2018.11.207

JEITA (Japan Electronics and Information Technology Industries Association). (2013). Promoting the green IT initiative in Japan. Retrieved March 5, 2021, from https://home.jeita.or.jp/greenit-pc/activity/asia/ file/Promoting_the_Green_IT_Initiative.pdf 
JEITA (Japan Electronics and Information Technology Industries Association). (2016). Current status and future of IT equipment's trends and energy efficiency. Retrieved March 5, 2021, from https://home. jeita.or.jp/greenit-pc/activity/seminar/160708/pdf/3-1.pdf (In Japanese)

L.1410. (2014). Methodology for environmental life cycle assessment (LCA) of information and communication (ICT) goods, networks and services. International Telecommunication Union

Masui, T., Rana, A., \& Matsuoka, Y. (2003). AIM/material model. In M. Kainuma, Y. Matsuoka, \& T. Morita (Eds.), Climate policy assessment (pp. 177-196). Springer. https://doi.org/10.1007/ 978-4-431-53985-8

Matsumoto, K., \& Masui, T. (2011). Analyzing long-term impacts of carbon tax based on the imputed price, applying the AIM/CGE model. Management of Environmental Quality, 22(1), 33-47. https://doi.org/ $10.1108 / 14777831111098462$

L.1451. (2019). Methodology for assessing the aggregated positive sector-level impacts of ICT in other sectors. International Telecommunication Union

METI (Ministry of Economy, Trade and Industries). (2019). Preliminary report on indices of industrial production. Retrieved March 5, 2021, from https:/www.meti.go.jp/statistics/tyo/seidou/result/ichiran/08_ seidou.html\#menu6

Metz C. (2017) Tech giants are paying huge salaries for scarce A.I. Talent. Retrieved March 5, 2021, from https://www.nytimes.com/2017/10/22/technology/artificial-intelligence-experts-salaries.html

MIC (Ministry of Internal Affairs and Communications JAPAN). (2009). Input-output tables for Japan. Retrieved March 5, 2021, from https://www.e-stat.go.jp/en/stat-search/files?page=1\&layout=datalist\& toukei $=00200603 \&$ tstat $=000001026283 \&$ cycle $=0$

MIC Research Institute Ltd. (2018). Cloud SI market status and outlook. MIC Research Institute Ltd. In Japanese.

MICa (Ministry of Internal Affairs and Communications JAPAN). (2019). Information and communications in Japan WHITE PAPER 2019. Retrieved March 5, 2021, from https://www.soumu.go.jp/johotsusin tokei/whitepaper/eng/WP2019/2019-index.html

MICb Research Institute Ltd. (2019). The current state and future of the expanding industrial PC market with edge computing. MIC Research Institute Ltd. In Japanese.

MOFA (Ministry of Foreign Affairs of Japan). (2015). Intended nationally determined contribution (INDC): Greenhouse gas emission reduction target in FY2030. Retrieved March 5, 2021, from https://www. mofa.go.jp/ic/ch/page1we_000104.html

Moyer, J. D., \& Hughes, B. B. (2012). ICTs: Do they contribute to increased carbon emissions? Technological Forecasting and Social Change, 79(5), 919-931. https://doi.org/10.1016/j.techfore.2011.12.005

Nagao, T., Hara, M., Hannoe, S., \& Nakamura, J. (2017). Estimation of reduction in $\mathrm{CO}_{2}$ emissions by using ICT throughout Japan. In M. Matsumoto, K. Masui, S. Fukushige, \& S. Kondoh (Eds.), Sustainability through innovation in product life cycle design (pp. 633-649). Springer. https://doi.org/10.1007/978981-10-0471-1_43

NEDO (2016) Society implementation vision on next-generation artificial intelligence technology. Retrieved March 5, 2021, from https://www.nedo.go.jp/content/100782828.pdf (In Japanese)

Nikkei BP (2016) Road map 2016-2025 ICT integrated new industry. (In Japanese)

NTT (Nippon Telegraph and Telephone Corporation). (2010). PSTN migration general outlook. Retrieved March 5, 2021, from https://www.ntt-west.co.jp/news_e/1011/pdf/101102a_1.pdf

Okubo T. (2020) COVID-19 and teleworking in Japan. Retrieved March 5, 2021, from https://voxeu.org/ article/covid-19-and-teleworking-japan

Oshiro, K., Masui, T., \& Kainuma, M. (2017). Quantitative analysis of Japan's 2030 target based on AIM/ CGE and AIM/Enduse. In S. Fujimori, M. Kainuma, \& T. Masui (Eds.), Post-2020 climate action. Global and asian perspectives (pp. 143-156). Springer.

Oulton, N. (2002). ICT and productivity growth in the United Kingdom. Oxford Review of Economic Policy, 18(3), 363-379. https://doi.org/10.1093/oxrep/18.3.363

Palvia, P., Baqir, N., \& Nemati, H. (2017). ICT for socio-economic development: A citizens' perspective. Information \& Management, 55(2), 160-176. https://doi.org/10.1016/j.im.2017.05.003

PERSOL. (2020). The 3rd urgent investigation on the impact of new coronavirus countermeasures on telework. Retrieved Jul 16, 2021, from https://rc.persolgroup.co.jp/thinktank/research/activity/data/telew ork-survey3.html (In Japanese)

Pohl, J., Hilty, L. M., \& Finkbeiner, M. (2019). How LCA contributes to the environmental assessment of higher order effects of ICT application: A review of different approaches. Journal of Cleaner Production, 219, 698-712. https://doi.org/10.1016/j.jclepro.2019.02.018

Takahashi, K. I., Tatemichi, H., Tanaka, T., Nishi, S., \& Kunioka, T. (2004). Environmental impact of information and communication technologies including rebound effects. Advance Online Publication. https://doi.org/10.1109/ISEE.2004.1299680 
Zhang, X., Shinozuka, M., Tanaka, Y., Kanamori, Y., \& Masui, T. (2020). Forecast of future impacts of using ICT services on GHG emissions reduction and GDP growth in Japan. In Y. Kishita, M. Matsumoto, M. Inoue, \& S. Fukushige (Eds.), EcoDesign and sustainability II. Sustainable production, life cycle engineering and management (pp. 207-222). Springer. https://doi.org/10.1007/978-981-15-6775-9_14

Publisher's Note Springer Nature remains neutral with regard to jurisdictional claims in published maps and institutional affiliations. 